\title{
Summarizing Epic
}

\author{
Frederick Turner
}

Founders Chair Professor (Former), School of Arts and Humanities, University of Texas at Dallas Email: frederick.turner@gmail.com

\begin{abstract}
It is claimed that the literary humanities are profoundly compromised and may even be irrelevant, that the appeal of literature is quixotic and anachronistic at best. I argue that there is life in the old dog yet. In the genre we set aside and dismissed, i.e., epic, the oldest one of all, may be found the revival of literary studies; and close by is the whole burgeoning, vital, and chaotic world of current popular epic, of big-screen action and fantastic cybernetic games, that sorely needs a rooting and a clarifying guide.
\end{abstract}

Keywords: Epic, Gaming, Storyteller, Theory

\section{The Quest for Literature}

From two basic themes-freedom and the knowledge of death--flow all the essential elements of epic: the hero, the quest, the natural man, the fall, the kin struggles, the deathworld journey, the city founding, and so on. ${ }^{1}$ The recipe for freedom-as-knowledge runs as follows:

(A) First take a storyteller, a knower, the very fact that there is someone who knows something. Let that knower acknowledge the prior and independent existence of what is known, but become the voice of prior knowers of that known world, and of knowledge itself.

(B) That storyteller must show how the various degrees of freedom, from simple temporal difference between what was before and what comes after, through involuntary animal intention to human conscious decision, emerged in the course of creation. This amounts to an implied or explicit history of the universe. The coherence and necessity of that history, its evolutionary intelligibility, the demonstrable failure of other ways to our condition, are the strength of the case the storyteller must make.

(C) There must be a prototypical representative of the human race, the hero, who is part animal, part human, and part divine (or hero twins, who split these parts between them). He must embody authentically the human paradox of being both an exceptional and transgressive individual and the norm of his species, culture and community. His birth is a mystery that can only be solved retrospectively, and whose solution leads to great

\footnotetext{
${ }^{1}$ See the list of world epics and epic themes at the end of this essay. 
dangers and rewards. The hero must encounter some opening, a question or problem that cannot be solved in the terms that the status quo offers, and that affords an elusive goal that may change as the quest proceeds. This quest necessitates a journey, in which the hero is torn between nostalgia and the thrill of enterprise. The journey is full of conflicts in which the ability to turn life into a game is essential to survival and success, or at least to a significant and fitting end. We humans are born walkers, and thus born explorers; epic records the trials and prizes of that vocation. Human freedom, at least in part, is mobility itself; we know by going there and seeing for ourselves. The eye and the foot, as in Oedipus' name, are bound together in the paradoxes of knowledge and freedom.

Human beings are also the product of a unique kinship system, involving big brains, extended infancy, bonding of different kinds, marriage, in-laws, an incest taboo, adolescence, menopause, and longevity (especially female longevity). To know is also to know in the biblical sense. Kinship is itself a branchy and open-ended but rule-governed plan of classification, and is thus a paradigm and template of any free ordered system. The epic hero is usually embroiled in the complexities of this system, that both hamper and help to define the achievement of meaning in the quest. In the process of the quest the three aspects of human life-the natural, the cultural, and the spiritual--are defined through action and story, and a quasi-legal language of covenant among them is postulated. The very fact of there being magisteria or regimes that are not reducible to each other is a primary prerequisite for freedom; there is always choice when there is the prior choice of which set of rules to obey. Of course, having different masters is less comfortable than pure servitude, but here knowledge is a great solace at least. And one's voluntary loyalty in the presence of alternate allegiances may be rewarded. The crucial leap in human evolution was from animals to human animals (not an outdated issue: it is currently being explored by a variety of scientific disciplines in the prehistoric caves of South Africa). That leap, by which we were enabled to look back at ourselves in the mirror of our language, is explored in epic through the paired stories of the battle with natural or animal man, and the natural man's fall from the natural state into culture and knowledge. With this step in the epic recipe a wealth of flavors is released, with subsidiary tales of sex, shame, clothes, drugs, technological invention, domestication of animals and plants, and the knowledge of death.

With the fall into knowledge comes death, and the epic hero must go through the experience of death in his journey into and back from the underworld. The games that gave him his "game face" in his heroic strife now return as part of the set of magics that enable him to enter the land of shades with some chance of return, a set that also includes a spirit guide, and a talisman that is often the musical instrument of the oral poet. In the underworld the hero-now a hero-poetspeaks with the dead. The conversation establishes the essential communicative link between the dead and the living that enables humans, unlike all other animals, to accumulate knowledge rather than just fill up an inherited potential in every generation, as other advanced animals already do. It provides information about past history, prophecies of the future, assigned duties and the basic structure of the rituals of funeral that are universal among human societies. The hero is freed from death by death; the mystery of the human experience of time becomes a way to question death's finality. 
The ground is now prepared for city-building, and the essential ground rules that make a city a city must be set in place: its walls and gates; its qualifications for belonging; a sacrificial system for building basic mammalian drives into higher, more abstract, and more voluntary moral vocabularies and laws; the founding of rituals such as marriages, funerals, food practices, and initiation rites; money; genealogies; a common language; geographical identifiers and locators; calendars; and legal systems. Home is where we are free, and where we know and are known: what are the constraints, what is the syntax of that condition of being at home? The city has a history, and must free itself from the tyranny of myth while preserving its wisdom. The contradictions between rulership and herohood must be explored. National character and national destiny must be defined, so that collective cultural self-knowledge can correct for collective cultural choice of goals and aims.

The actions of the story must not simply be adventures-epic is not the same as picaresque. They must be significant, though not too obtrusively and univocally allegorical. The events of the story and the decisions of the hero must enlist both our natural sentiments and our judgements of consequential and logical entailment, so as to develop the core values of a working culture. Those value oppositions-good/bad, right/wrong, firstness/secondness, beautiful/ugly, playful/serious, etc--must be distinguished from each other so as to allow a rich palette or scale or vocabulary for capturing important and decisive factors in making judgements. Here the moral value of free choice and the veridical value of discernment are united and integrated. The epic as a whole must be made to refer back to its own medium of communication and to the history of that medium, as human expression emerged from muteness to speech, writing, print, and new media. It must, since it is concerned with the process of valuing itself, relate its story and literary form to the very currency of its society's economy, and to the fixing of the standard language. It must address not only in content but in form the establishment, reform, and transformation of the national religion (or suite of allowed religions).

Finally, in the presentation or "plating" of the epic feast, the key and guide must be memory and the arts of memorability, since the deepest freedom we have is the freedom to change ourselves, not just our actions; and memory is a physical change in the nature of our brains and bodies. Knowledge is memory. We must be able to change not only the contents of our thoughts but also the container of them. And it is only such changes that truly constitute knowledge. As humans our deepest pleasures, thanks to our evolution that gave us such rewards, are in just such transformations of ourselves. So indeed are our greatest pains: but the pleasures outweigh the pains. The colloquial use of the term "epic" by today's young is actually an important if obvious defining characteristic of the genre. An epic simply has to be big. Why? One reason is that if epic is to become part of our memory it must be experienced as a place one has inhabited for a substantial amount of time, something we have imaginatively started to explore and move about in. It is not taken in to the mind as a precious acquisition, a jewel for the jewel box, as a beautiful lyric can be. Instead, it must take us in, make us feel at home in it, make us look out at the world from it, rather than be looked at and lovingly examined in its glass case. Time and familiarity themselves ingrain a thing into memory. We must live in epic country for a while for it to work its transformation on us. A second reason for the magnitude of epic is that the genre purports to be comprehensive for its culture. It is about the parts of a culture, like any story, but it is also about the whole. The pervasiveness of lists in epic is no coincidence. When the Heike names all thirty 
leading members of the Heike who fled Kyoto in 1183 and all sixty-seven commanders of the Genji armies at the battle of Mikusa, or the Cattle Raid of Cooley names the seventy places that the armies of Medb and Aillill passed through in their invasion of Ulster, or the Iliad names all the Greek ships, or the Popol Vuh names all the ranks and titles of the Cauecs, the Greathouses, the Quichés and the Zaquics, ${ }^{2}$ something beyond an obsession with details is going on. Part of the answer is that epic tries to include all the people and places where its writ is to run, it is inclusive, like a census. Nobody on the epic list can defect, because he is part of the story, is thus partly responsible for the way things are now, and shouldn't complain. He or his representative ancestor or place of origin chose this fate and has to live with it.

But further, epic tries to give a sense of the vastness, the cosmic scale, of its story. Such lists bury us deep in a huge fabric, out of sight of the center and far also from the edge of the world. Thus, when we do come to its edge in the climactic scenes, we are fully aware of how massive, how weighty, is the shore we stand upon. All else has been summed up and comprehended; we have put all that behind us, but it backs us nevertheless. Nothing has been left out, so that when we do confront the nothing beyond the edge, it is genuine, not fake: we are truly in danger of being lost, because where we are is not in the list of all that we know. Even a very big novel (unless it has crossed the epic threshold, like Moby Dick) does not give us that same sense of frightening comprehensiveness. In the novel the social world embraces us still. When the characters settle down from their youthful adventures, or give up their fight against the expected, or die, the waters of the social world, which after all has determined everything that has happened, close over their heads,

Till human voices wake us, and we drown ${ }^{3}$

and all is as it was before. Even the most horrific and cynical detective novel cannot, though it try, escape the conventions of class, psychological realism, worldly wisdom; every detective novel is a "cozy" at heart, even if Miss Marple has morphed into an alcoholic and suicidal Swedish left-wing charismatic loser cop. Epic, with its atrocious naivety, its huge flaws in respect of realism, its monstrous ambition, its eerie contacts with Nature and the Gods, is the old true magical realism that actually takes us to the edge of things.

With all its magnitude, however, epic must still respond to Aristotle's demand that the epic plotline must have a fundamental unity, an epic story depicts a single large action. That action can bemust be--broken up into many smaller actions and subdivided further into incidents and "beats." The term "action" itself can be stretched: the Shahnameh has many stories, many climaxes, but there is an underlying tragic current upon which floats the glory of Persia; the epic of the Three Kingdoms swarms with hundreds of characters and narratives, but still keeps its grand trajectory of the restoration of Chinese unity.

\footnotetext{
${ }^{2}$ Heike, pp. 251, 299; Cattle Raid of Cooley, pp.18-21; Iliad, 2.492-759; Popol Vuh, pp. 184-185.

3 T. S. Eliot: "The Love Song of J. Alfred Prufrock," last line.
} 


\section{Conclusion}

At this time of writing, it is "a truth universally acknowledged" that theory is dead, that the literary humanities are profoundly compromised and may even be irrelevant, that the appeal of literature is quixotic and anachronistic at best. I argue that there is life in the old dog yet. In the genre we set aside and dismissed, the oldest one of all, may be found the revival of literary studies; and close by is the whole burgeoning, vital, and chaotic world of current popular epic, of big-screen action and fantastic cybernetic games, that sorely needs a rooting and a clarifying guide. That world makes a virtue of creative anachronism, and creative anachronism is the stock-in-trade of the epic world. The study of literature can perhaps revitalize itself by arranging and celebrating the marriage of the two worlds. We live now in a global culture, and our probes and satellites have enabled us to see the world as a whole. Despite the fact that after our first foray to another world we seem to have fallen back into local concerns, the time is coming when we need to deal imaginatively, and in solidarity as humans and representatives of earthly life, with what is profoundly other. Epic may help us overcome the obscure diffidence or suppressed panic wherewith we turned back from the big quest. That quest will surely get us into trouble, as Odysseus got into trouble. But there is nowhere else to go. 